Progress Report

on

\section{Natural and Anthropogenic Climate Changes}

Contract DE-FG02-86ER60422

$$
\begin{aligned}
& \text { Prepared by } \\
& \text { W.-C. Wang } \\
& \text { B. Ronberg } \\
& \text { W. Gutowski } \\
& \text { D. Gutzler } \\
& \text { D. Portman }
\end{aligned}
$$

Atmospheric and Environmental Research, Inc. 840 Memorial Drive

Cambridge, MA 02139

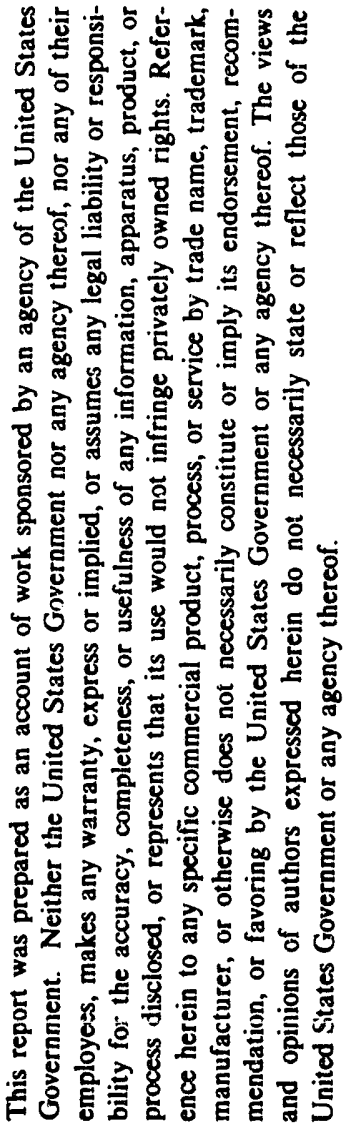

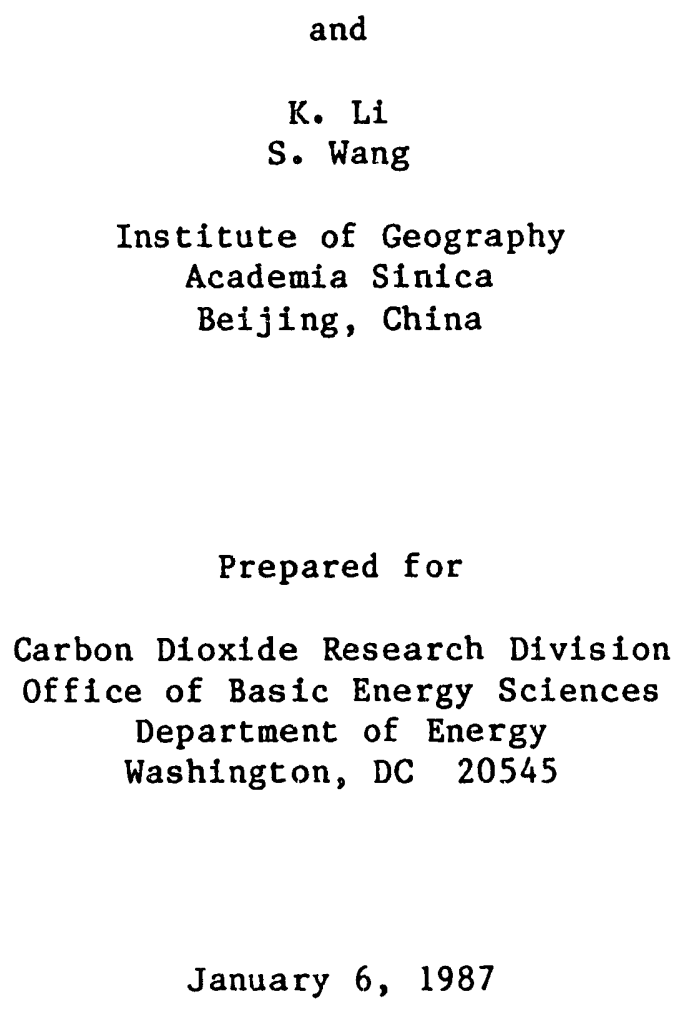

and

K. $\mathrm{Li}$

S. Wang

Institute of Geography

Academia Sinica

Beijing, China

Prepared for

Carbon Dioxide Research Division

Office of Basic Energy Sciences

Department of Energy

Washingt on, DC 20545

January 6, 1987 
The project includes three components

1. Analysis of climate data in U.S. and China to study the regional climate changes;

2. Analysis of general circulation model simulations of current and CO2-doubled global and regional climates; and

3. Studies of desertification in the United States and China.

\section{Analysis of Climate Data}

The task attempts to identify climate patterns on a regional scale from measurement and proxy data in the United States and China. The climate pattern includes the spatial scale of climate regions and their temporal patterns, and interregional relationships. The results will improve our understanding of regional climate and climate changes so that GCM simulated regional climate can be evaluated.

The major focus so far has been on the evaluations of statistical techniques suitable for use in the data analysis. The techniques include principal component analysis and cluster analysis to identify climate patterns and factor analysis with rotation to study interregional relationships. An example is shown in Fig. 1, which describes the interrelationship among three climate regions and the near surface flow responsible for the relationship is also shown. Details of the study have been documented in Ronberg and Wang (1987, J. Climatology, in press).

A second effort involves a comparative study of rainfall patterns over China between 1880-1979 and 1600-1699; the latter period is part of the Little Ice Age. As shown in Fig. 2, we found that the climate patterns were markedly dissimilar, thus suggesting different circulation patterns during the two periods. Three dry patterns common to these two periods are shown in Fig. 3 .

We are currently analyzing the pressure, temperature, and precipitation data of the 60-station network for 1951-1979 in China. In addition, much more effort will be spent on using the 1200-station temperature and precipitation data in the U.S. to identify the climate regions.

\section{Analysis of GCM Results}

We have begun a study comparing regional statistics for simulated current (contro1) and doubled-Co2 climates from models developed at the National 
Center for Atmospheric Research (NCAR), the Geophysical Fluid Dynamics Laboratory (GFDL), and the Goddard Institute for Space Studies (GISS). We are diagnosing the physical processes responsible for differences between the modelsimulated climates. We compare the latitudinal variation of zonal-mean statistics and averages over limited sectors in the various model simulations, for the seasons December-January-February (DJF) and June-July-August (JJA). The sectors examined cover the United States (Fig. 4), China (Fig. 5), and selected ocean regions.

Preliminary results suggest that the latitudinal variations of zonal means for the observed current climate are qualitatively simulated by each model's control climate. However, on regional scales there are significant quantitative differences between the model control climates and in their responses to doubled $\mathrm{CO}_{2}$. Fig. 6 shows comparisons of JJA-average surface air temperature and precipitation for the central United States and southeast China sectors. There is better agreement between models for the chinese sector, perhaps reflecting the moderating influence of the nearby ocean. Over the central United States, differences between current climate simulations are as large as the changes associated with doubling $\mathrm{CO}_{2}$, indicating the difficulty of extracting a reliable climate change signal. Especially noteworthy are the substantial disparity between GISS and NCAR climates and the much larger GFDL response to $\mathrm{CO}_{2}$ doubling compared to other models. Diagnosis of these differences using heat and moisture budgets is in progress.

\section{Desertification}

We are in the process of finishing the manuscript entitled "Climate and Desertificiation: A review." The paper reviews the studies concerning climate over arid and semiarid regions around the globe and will be published as a DoE Technical Report. We plan to get into the second stage of the study of climate and desertification: the water budget study over desert regions in China. 


\section{Captions}

Figure 1. Interregional relationship for a selected factor pattern as derived from 120-station (in dots) proxy precipitation records for the period 1950-1979. Hatching designates significant positive valued areas which may be related to the flow patterns indicated by the arrow.

Figure 2. Climate regions derived from statistical analyses of proxy precipitation records for (a) 1880-1979 and (b) 1600-1699. Dotted circles denote stations reclassified into different regions, and shadings denote regions undergoing marked changes. The patterns of the regions suggest that the circulation changed from the meridional flow during the Little Ice Age to zonal flow during recent years.

Figure 3. Three dry patterns common to 1880-1979 and 1600-1699. The different shadings from the coarsest to finest represent drought, dry, moist, and flood conditions, while white areas denote normal conditions.

Figure 4. United States analysis sectors defined for (a) the GISS model and (b) the GFDL and NCAR models. GISS regional means are weighted by the fraction of land in each grid box.

Figure 5. Same as Figure 4, but for China. The GFDL southeast China region includes a land grid box that is ocean (and hence ignored) in the NCAR southeast China region.

Figure 6. Surface air temperature and precipitation from each model's summer control climate and the difference between the doubled-CO2 and coitrol climates for (a) southeast China and (b) Central U.S. 

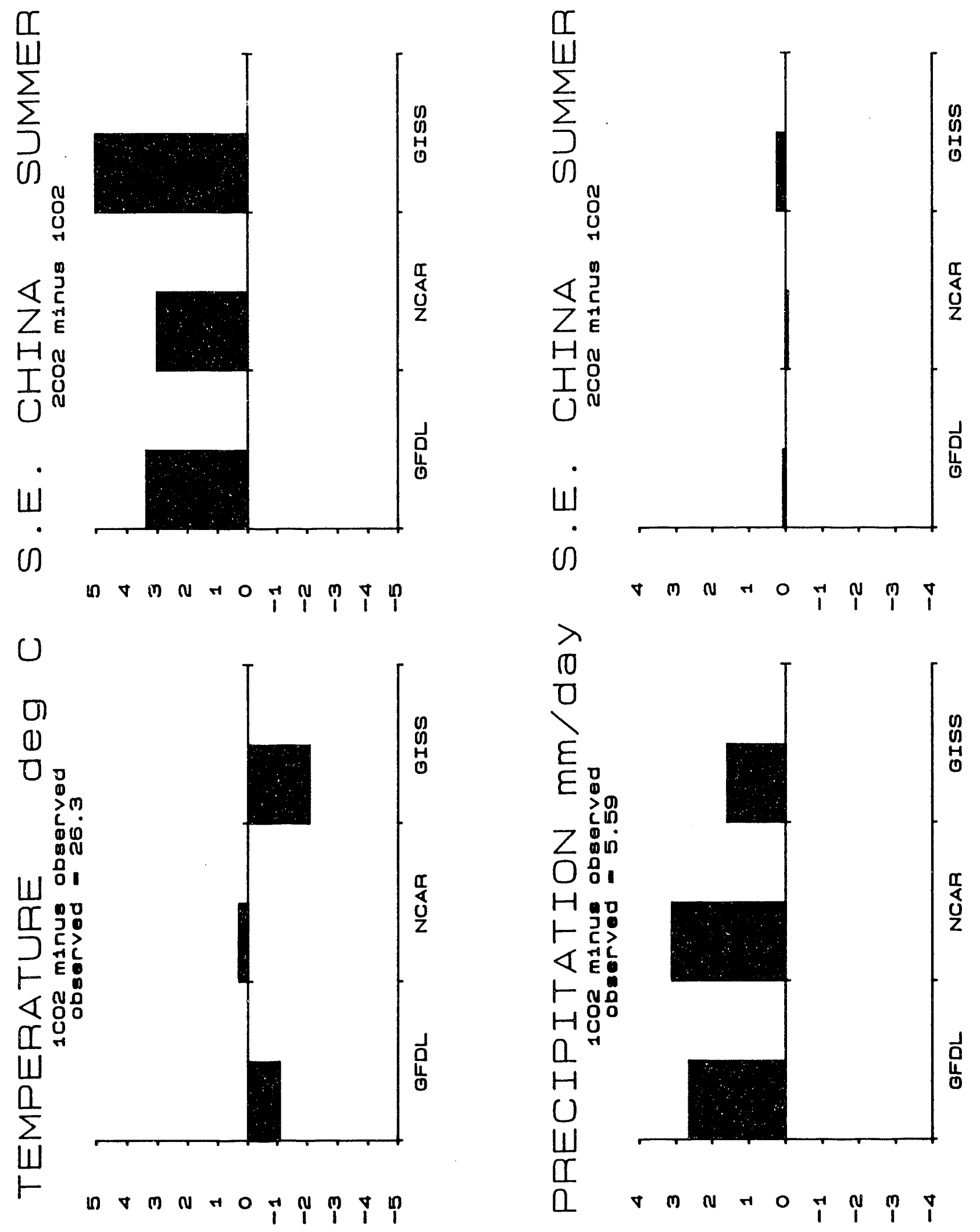

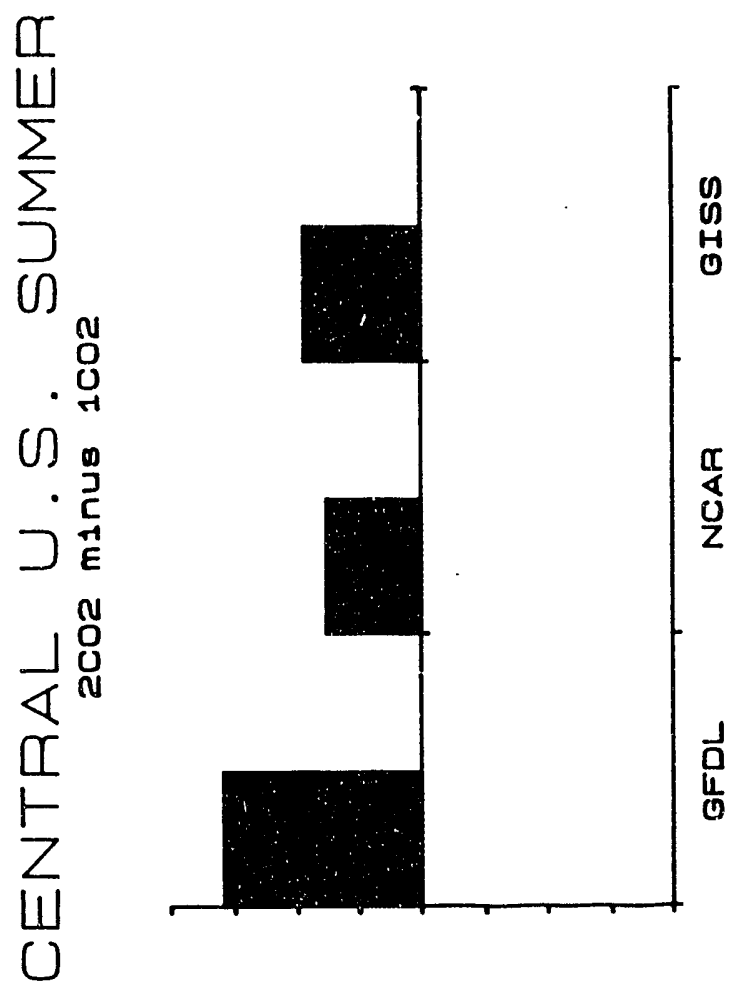

$\begin{array}{lllllllll}n & 0 & a & n & 0 & 1 & 1 & 1 & 0\end{array}$

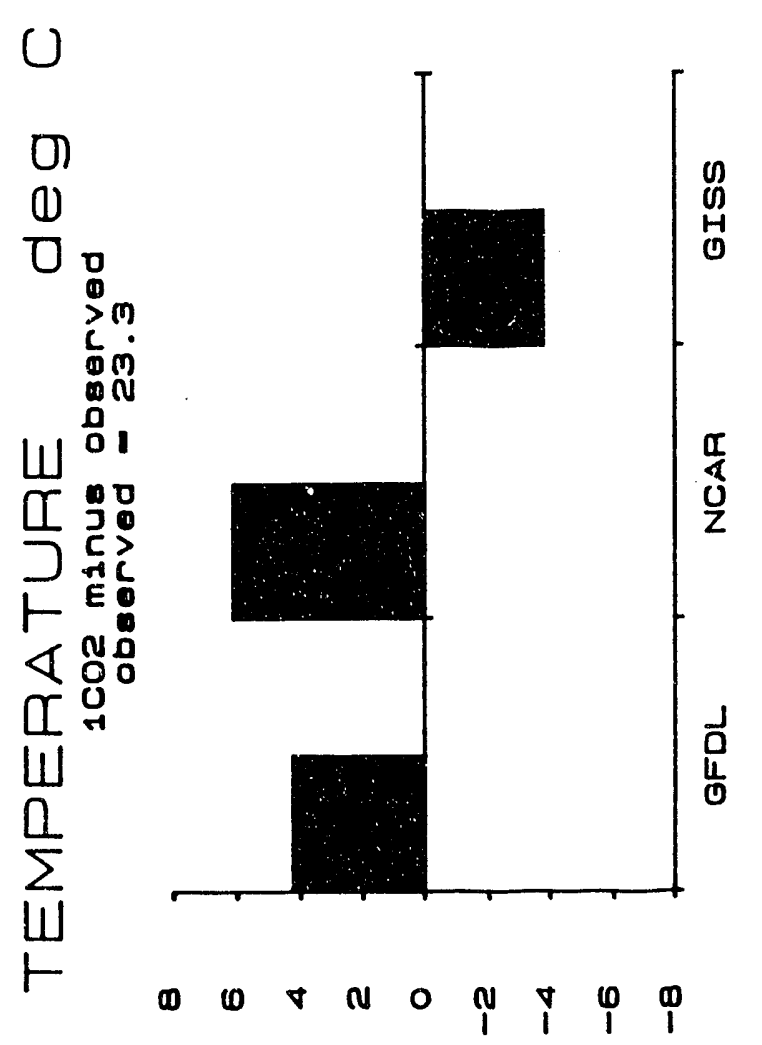

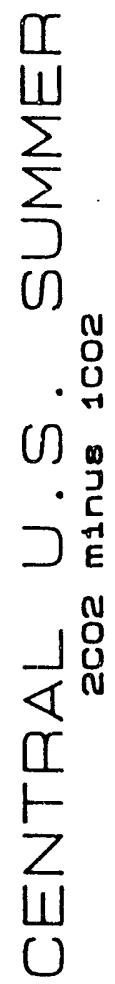

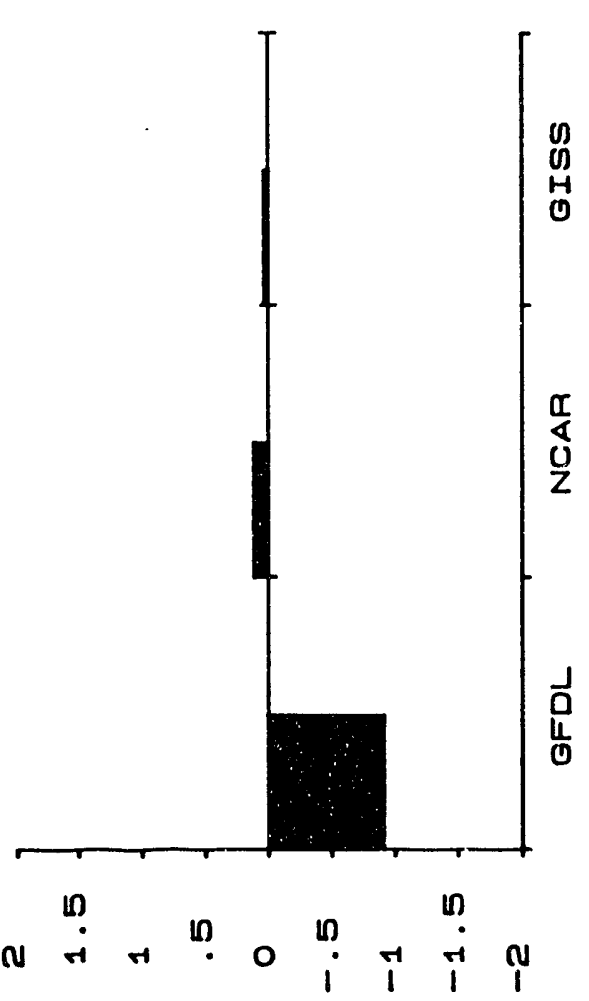

$\lambda$

10

0

$\varepsilon$

$E \stackrel{\square}{\square}$

$\sum_{0}^{0}{ }_{0}^{0}$ in

○.

H品

$\varangle \stackrel{+1}{E}$

十 ผ

$H$

$\mathrm{a}^{\mathrm{H}}$

1

0

แ

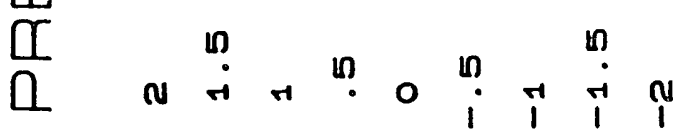




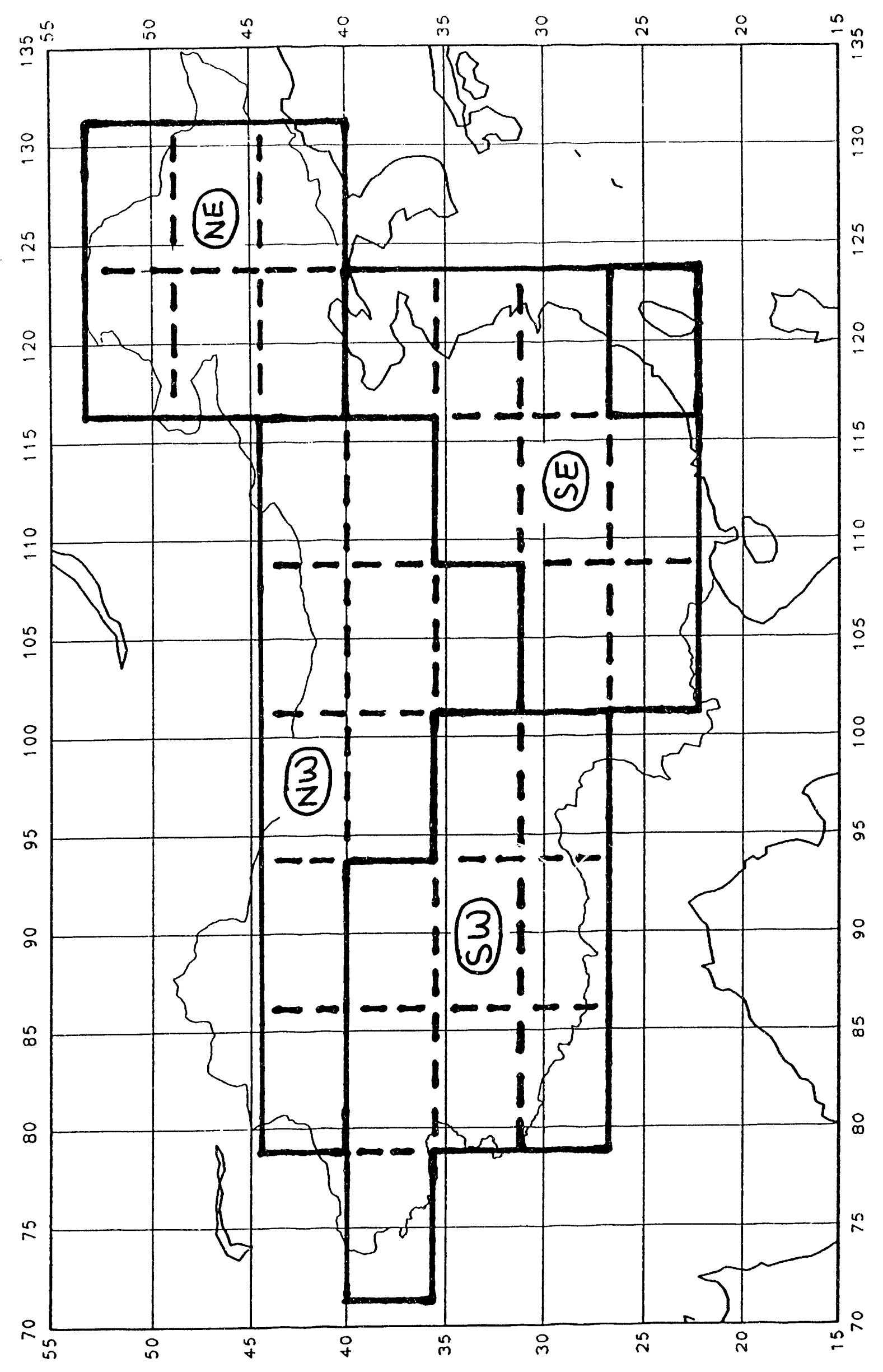




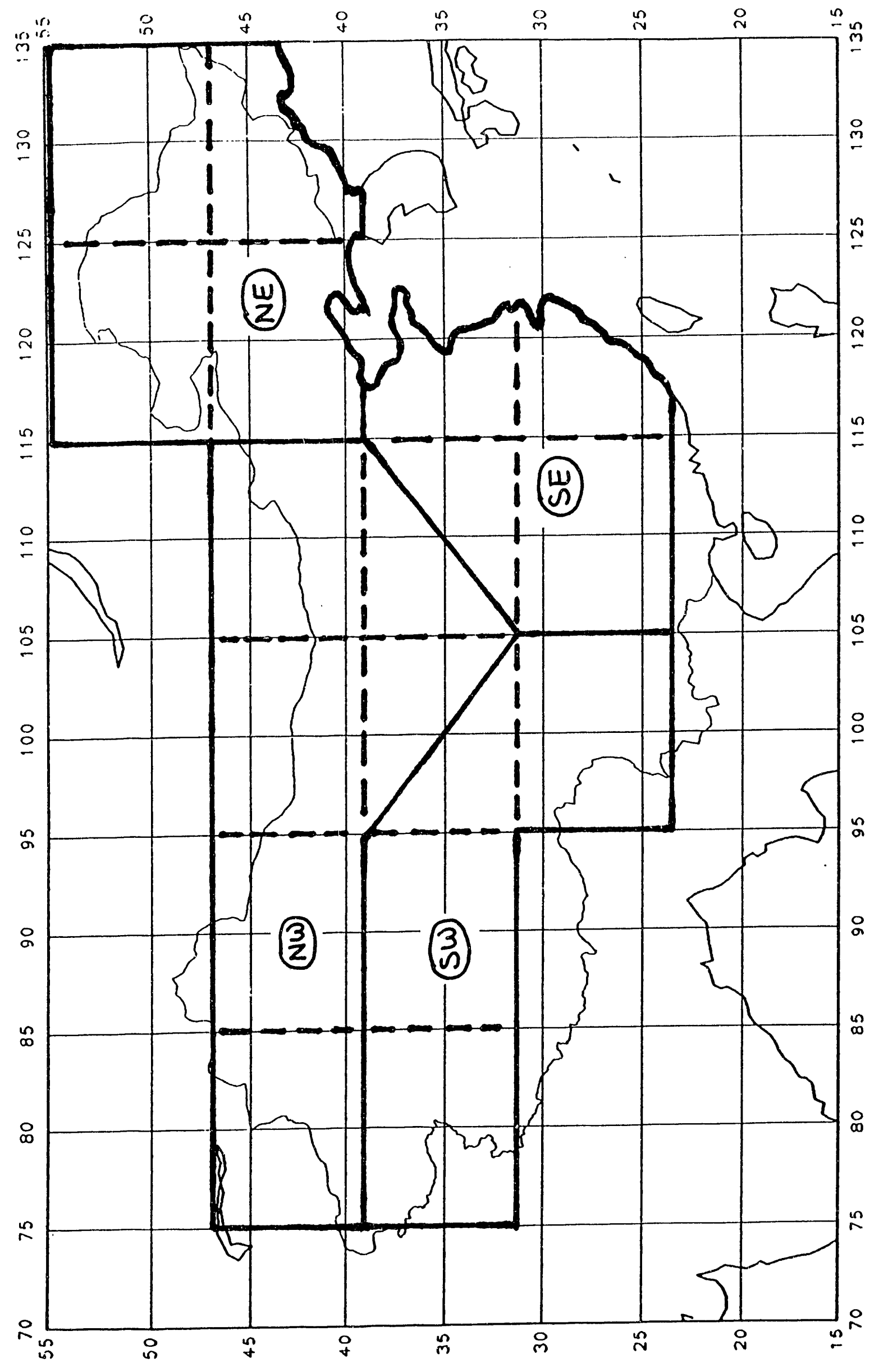

$E$ 


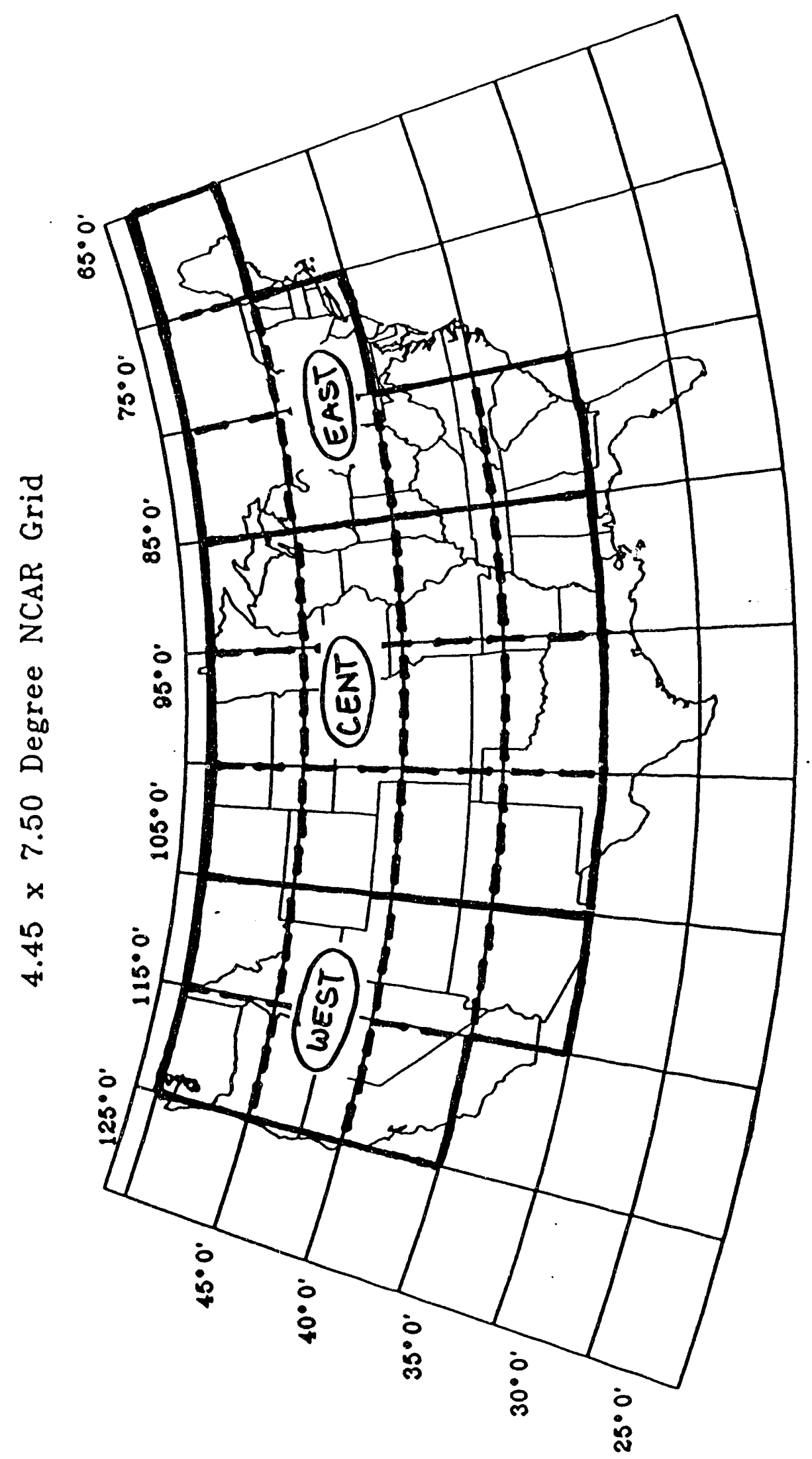




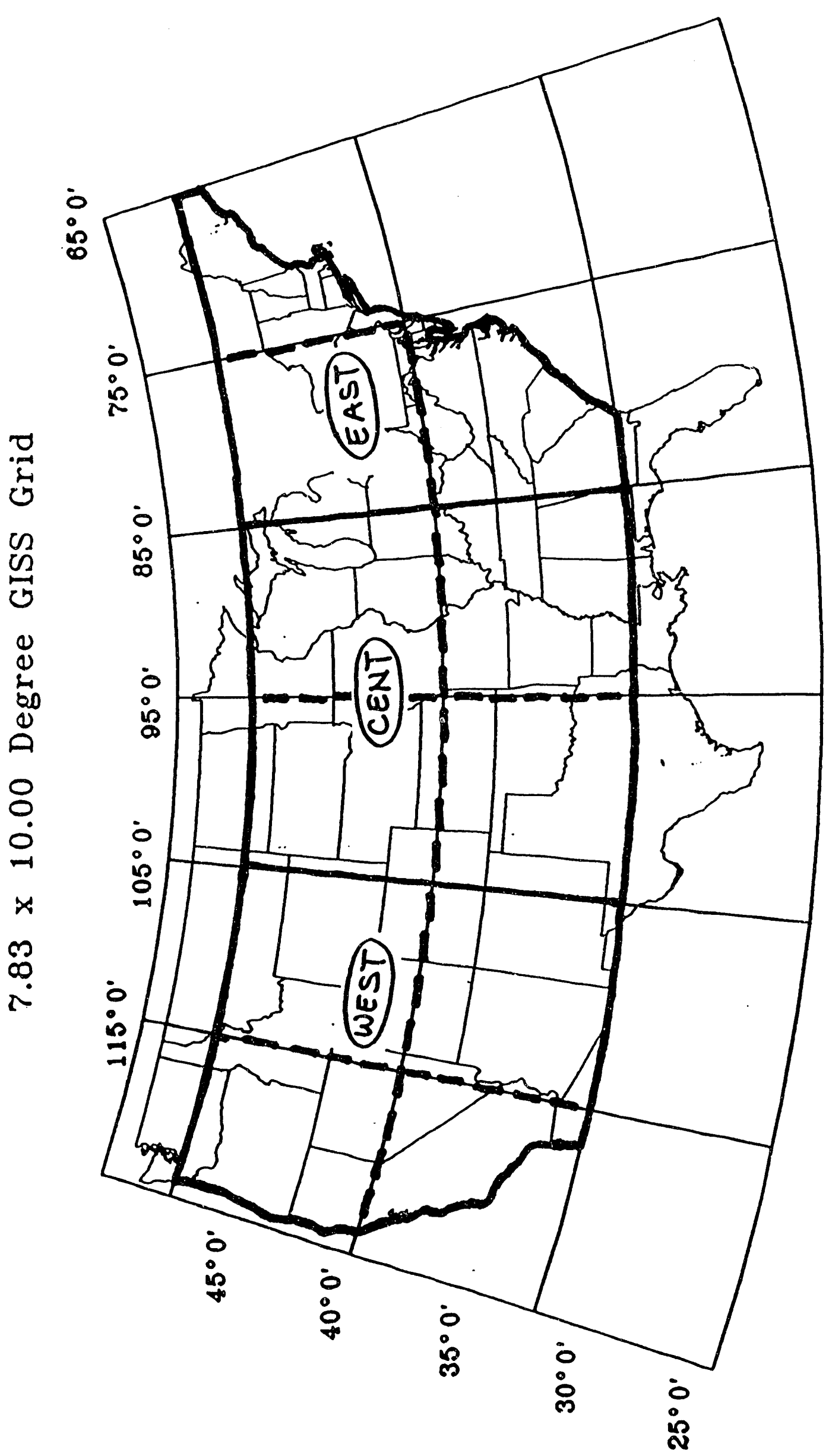




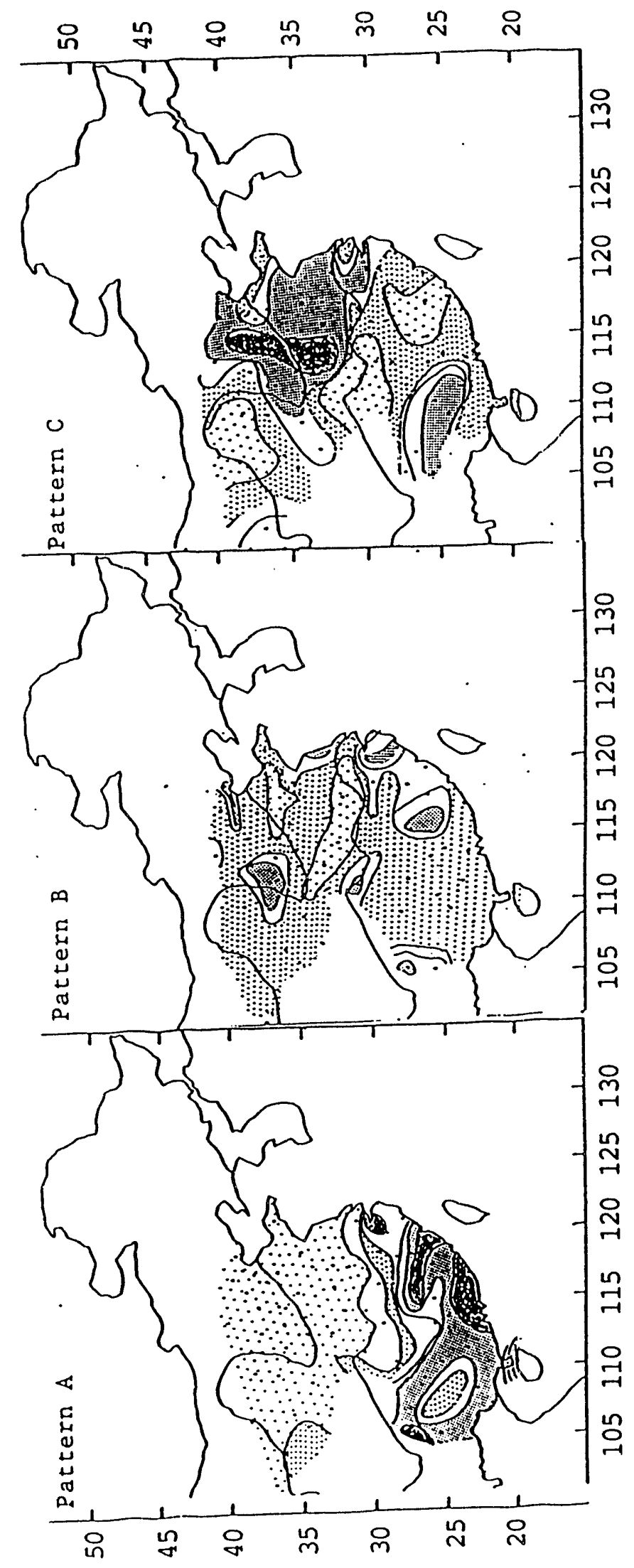




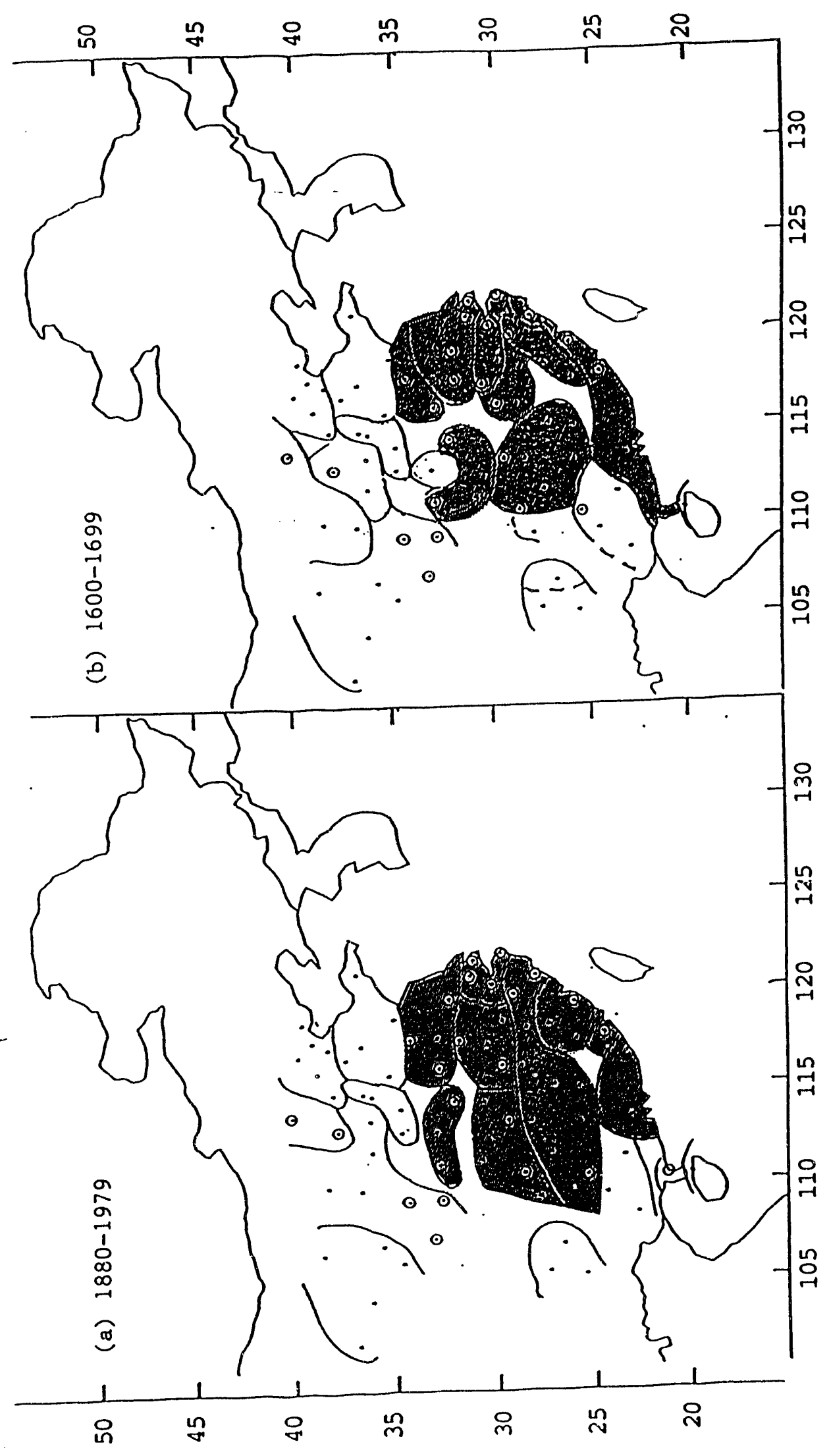




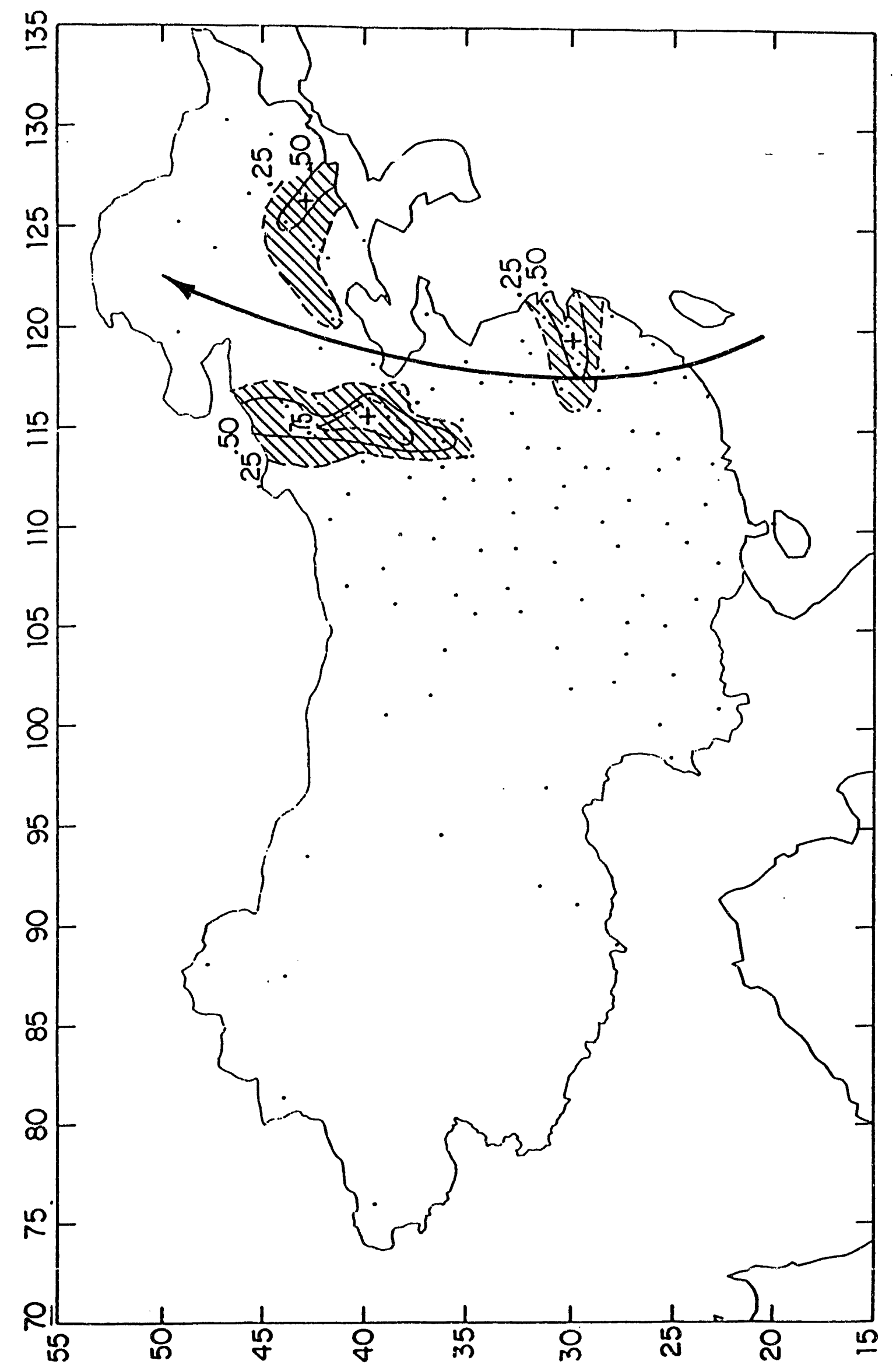



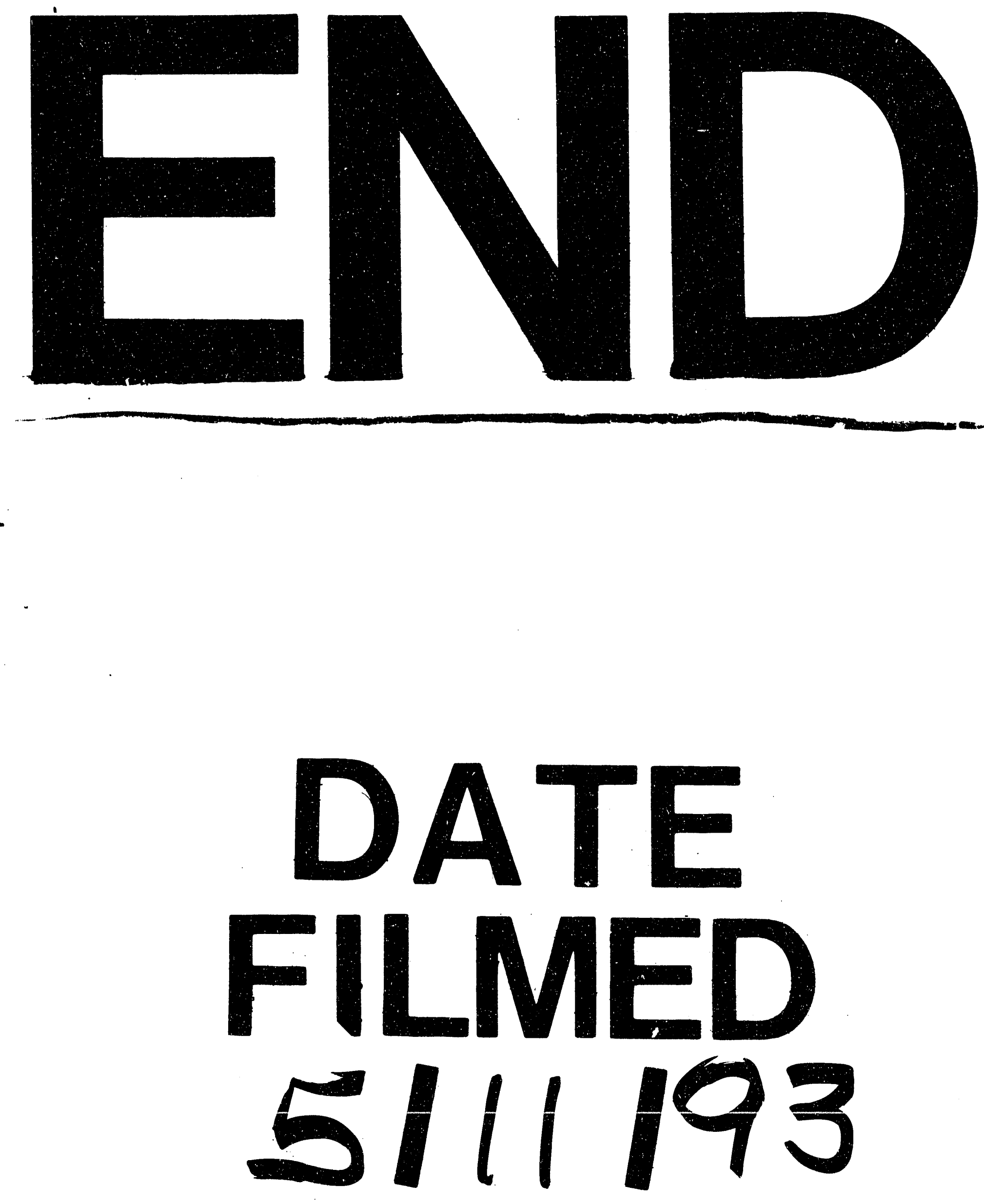
